\title{
Penerapan Model Arias pada Pembelajaran Kooperatif Tipe Think-Pair-Share (TPS) dalam Meningkatkan Motivasi Belajar dan Hasil Belajar Siswa Kelas VIII MTs Al-Amin Pakis
}

\author{
Wiwik Kusmawati \\ Program Studi Pendidikan Biologi, IKIP Budi Utomo Malang, \\ Jalan Citandui 46 Malang \\ e-mail: wiwikkusmawati@gmail.com \\ Purwaning Budi Lestari \\ Program Studi Pendidikan Biologi, IKIP Budi Utomo Malang \\ Jalan Citandui 46 Malang \\ Purwaning.budilestari@gmail.com
}

\begin{abstract}
This study aims to: (1) increase the motivation of class VIII student of MTs Al-Amin Pakis on the subject of growth and development, using the learning model of ARIAS at strategic cooperative learning Think-Pair-Share (TPS), (2) increase the yield class VIII student of MTs Al-Amin Pakis on the subject of growth and development, using ARIAS model study on cooperative learning strategies ThinkPair-Share (TPS). In this research is classroom action research (PTK/Classroom Action Research) by using a qualitative approach. The data analysis technique used to examine all the data that have been collected for researchers carrying out the practice of applying the learning model of ARIAS at learning strategies in the classroom TPS VIII through science lessons about growth and development in MTs Al-Amin Ferns. Data derived from the results of observations, interviews, tests and other data. Data analysis was performed through three steps: data reduction, a data display (presentation of data), conclusion drawing/verification (conclusion). Based on the analysis it can be concluded that: (1) the use of the learning model ARIAS on cooperative learning strategies Think-Pair-Share, can increase learning motivation eighth grade students of MTs Al-Amin Ferns in the subject of growth and development, (2) use ARIAS learning model on cooperative learning strategies Think-Pair-Share, can improve learning outcomes eighth grade students of MTs Al-Amin Ferns in the subject of growth and development.
\end{abstract}

Keywords : ARIAS, TPS, motivation to learn, learning outcomes

Pembelajaran merupakan suatu proses interaksi atau hubungan timbal balik yang terjadi antara pendidik dan peserta didik dalam penyampaian informasi atau materi agar tercapai tujuan pembelajaran yang efektif dan efisien. Permasalahan yang ada di negara Indonesia mencakup kurangnya mutu sumber daya manusia dan rendahnya mutu pendidikan yang ada. Beberapa upaya sudah dilakukan antara lain dengan pengadaan peralatan pembelajaran baik berupa buku maupun fasilitas pembelajaran, pelatihan peningkatan kompetensi para pendidik serta pengembangan kurikulum. Peran guru sebagai pendidik sebenarnya merupakan fasilitator penyampaian informasi yang berupa materi kepada peserta didik.
Berdasarkan observasi yang dilakukan di MTs Al-Amin Pakis pada pelajaran IPA siswa kelas VIII dengan Nilai Standar Kelulusan7. Guru IPA kelas VIII menyatakan bahwa pelajaran IPA begitu banyak materi yang harus dipahami dan dihafalkan. Materi pada kompetensi dasar yaitu pertumbuhan dan perkembangan, mengarahkan siswa agar lebih memahami faktor-faktor yang mempengaruhi pertumbuhan dan perkembangan makhluk hidup, perbedaan pertumbuhan dan perkembangan pada makhluk hidup, perbedaan metamorfosis dan metagenesis dan titik tumbuh pada bagian tumbuhan. Subyek penelitian merupakan siswa yang tahun ini duduk di kelas VIII. Kurang termotivasinya siswa terhadap pembelajaran 
akan menimbulkan berbagai masalah yang dihadapi, keadaan yang demikian ditunjukkan dengan siswa yang terlihat malas, ramai sendiri, mengganggu temannya, berjalan mondar-mandir, bahkan ada pula siswa yang sengaja tidak mengikuti pelajaran, sembunyi di kantin sekolah. Adanya suasana belajar diiringi dengan motivasi belajar yang menurun, berdampak pada hasil belajar yang kurang optimal. Upaya meningkatkan motivasi pembelajaran IPAkelas VIIIMTs Al-Amin Pakis perlu diterapkan metode pembelajaran yang inovatif dalam proses belajar mengajar yang memberikan kesempatan siswa untuk aktif. Adanya suasana pembelajaran yang memacu siswa sebagai faktor utama akan menarik siswa agar lebih mempunyai keinginan untuk merespon materi dan berinteraksi dengan peserta didik lainnya. Suasana pembelajaran yang menjadikan siswa saling berbagi pengetahuan baik ketika berdiskusi maupun menjawab pertanyaan pada saat presentasi.

Peningkatan motivasi belajar yang berpengaruh pada keaktifan siswa dapat menggunakan pembelajaran model ARIAS. Pembelajaran model ARIAS mampu menggerakkan siswa untuk lebih aktif dengan lima komponennya yaitu: Assurance (percaya diri), yaitu berhubungan dengan sikap percaya, yakin akan berhasil atau yang berhubungan dengan harapan untuk berhasil. Relevance, yaitu berhubungan dengan kehidupan siswa baik berupa pengalaman sekarang atau yang telah dimiliki maupun berhubungan dengan kebutuhan yang akan datang, Interest adalah yang berhubungan dengan minat/perhatian siswa. Assesment yaitu yang berhubungan dengan evaluasi terhadap siswa dan Satisfaction yaitu yang berhubungan dengan rasa bangga, puas atas hasil yang dicapai (Dewi, 2007).

Model pembelajaran yang memungkinkan siswa untuk berinteraksi satu sama lain adalah model pembelajaran kooperatif. Model pembelajaran kooperatif membantu siswa belajar setiap mata pelajaran mulai dari ketrampilan dasar sampai pemecahan masalah. Pembelajaran kooperatif memiliki beberapa tipe, salah satu tipe model pembelajaran kooperatif yang dapat membangun kepercayaan diri dan mendorong partisipasi mereka dalam kelas adalah model pembelajaran kooperatif tipe Think-Pair-Share (Widarti, 2007). Strategi pembelajaran kooperatif tipe Think-Pair-Share memberikan peserta didik lebih banyak waktu berfikir untuk merespon dan saling membantu. Guru hanya memperkirakan dan melengkapi penyajian singkat, sedangkan peserta didik membaca tugas atau materi pembelajaran yang belum diketahui. Pada saat proses belajar mengajar peserta didik tampak menuju pemenuhan sendiri kebutuhan intelektual dan mengembangkan individu berpotensi dengan melibatkan peserta didik sebagai pemikir dari pada pengumpul pengetahuan (Chotimah, 2009).

Olehsebabitu penelitiakan mengembangkan suatu pemecahan masalah untuk meningkatkan motivasi belajar dan hasil belajar siswa kelas VIII MTs Al-Amin Pakis dengan menggunakan penerapan pembelajaran model ARIAS dalam strategi pembelajaran kooperatif tipe Think-PairShare yang dinyatakan dalam judul penelitian "Penerapan Model ARIAS pada Strategi Pembelajaran Kooperatif Tipe Think-Pair-Share (TPS) dalam Meningkatkan Motivasi Belajar dan Hasil Belajar Siswa Kelas VIII MTs Al-Amin Pakis".

\section{METODE}

Teknik analisis data digunakan untuk menelaah semua data yang sudah terkumpul selama peneliti melaksanakan praktek menerapkan pembelajaran model ARIAS pada strategi pembelajaran TPS di kelas VIII A melalui pelajaran IPA tentang "Pertumbuhan dan Perkembangan" di MTs Al-Amin Pakis. Data yang berasal dari hasil observasi, wawancara, tes dan data lainnya. Analisis data dilakukan melalui tiga tahap yaitu: reduksi data, data display (penyajian data), conclusion drawing/verification (penarikan kesimpulan) (Miles dan Huberman dalam Susilo, 2009).

\section{HASIL}

\section{Hasil Penelitian Siklus 1}

\section{Motivasi Belajar}

Pemberian angket yang digunakan untuk mengetahui kondisi motivasi belajar siswa yang diberikan sebelum dilakukan tindakan dan sesudah siklus 1 . Analisa motivasi belajar siswa dapat dilihat pada tabel berikut: 
Tabel 1 Hasil pengukuran motivasi belajar siswa

\begin{tabular}{|c|c|c|c|c|c|}
\hline \multirow{2}{*}{ No. } & \multicolumn{2}{|c|}{ Sebelum PTK } & \multicolumn{2}{c|}{ Tindakan Siklus I } & \multirow{2}{*}{ Kriteria } \\
\cline { 2 - 5 } & Jumlah Siswa & Persentase (\%) & Jumlah Siswa & Persentase (\%) & \\
\hline 1. & 15 & 48,4 & 17 & 54,8 & Sangat tinggi \\
2. & 12 & 38,7 & 14 & 45, & Tinggi \\
3. & 4 & 12,9 & - & - & Sedang \\
\hline
\end{tabular}

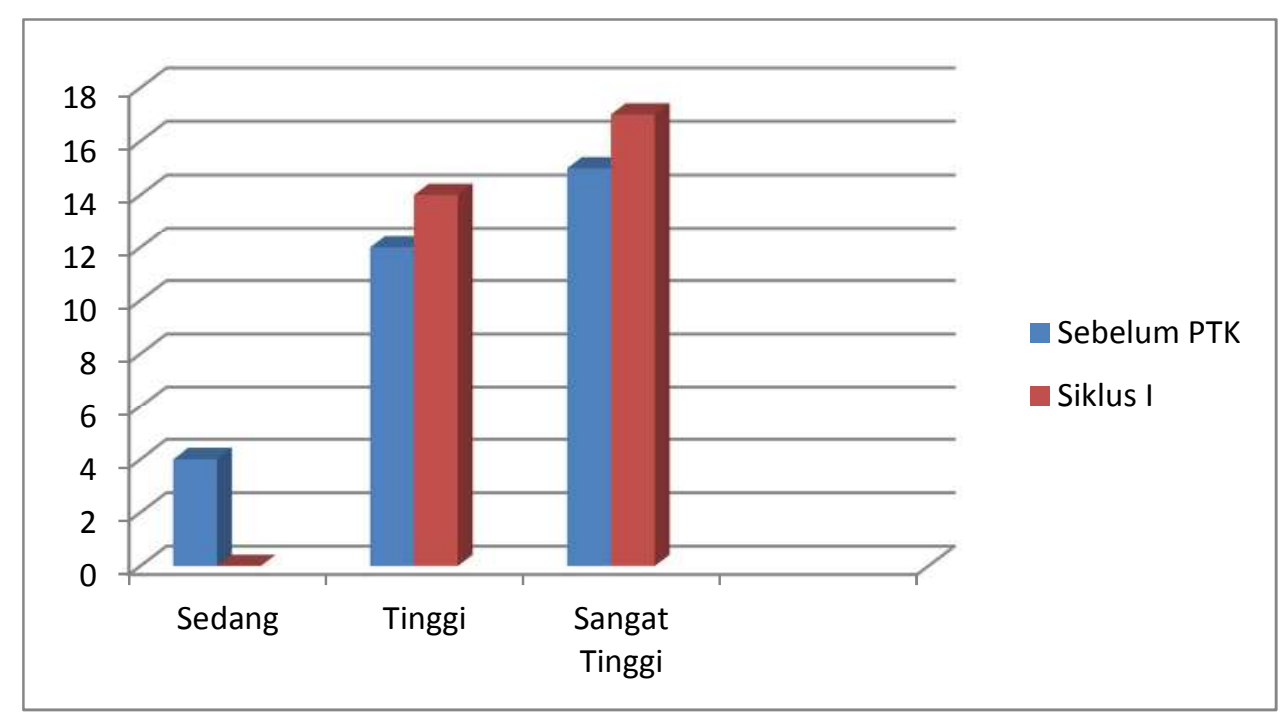

Diagram 1 Peningkatan motivasi belajar siswa pada siklus I

\section{Hasil Belajar}

Pemberian pos tes pada akhir siklus dilakukan untuk mengetahui perbandingan hasil be- lajar siswa sebelum dan sesudah diberikan tindakan. Berikut hasil analisa hasil belajar siswa berdasarkan hasil ulangan harian pada siklus 1:

Tabel 2 Hasil Belajar Siswa

\begin{tabular}{|c|l|c|c|c|c|}
\hline \multirow{2}{*}{ No. } & \multirow{2}{*}{ Nama } & \multicolumn{2}{|c|}{ Nilai UH sebelum PTK } & \multicolumn{2}{c|}{ Nilai UH siklus I } \\
\cline { 3 - 6 } & & Nilai & Keterangan & Nilai & Keterangan \\
\hline 1 & Aiga & 45 & Belum Tuntas & 50 & Belum Tuntas \\
\hline 2 & Anggi & 60 & Belum Tuntas & 53 & Belum Tuntas \\
\hline 3 & Sabil & 55 & Belum Tuntas & 42 & Belum Tuntas \\
\hline 4 & Daniel & 45 & Belum Tuntas & 65 & Tuntas \\
\hline 5 & Erika & 35 & Belum Tuntas & 67 & Tuntas \\
\hline 6 & Fadil & 50 & Belum Tuntas & 46 & Belum Tuntas \\
\hline 7 & Fajar & 50 & Belum Tuntas & 48 & Belum Tuntas \\
\hline 8 & Fara & 58 & Belum Tuntas & 45 & Belum Tuntas \\
\hline 9 & Farhan & 45 & Belum Tuntas & 67 & Tuntas \\
\hline 10 & Fariz & 55 & Belum Tuntas & 65 & Tuntas \\
\hline 11 & Fatimah & 52 & Belum Tuntas & 61 & Belum Tuntas \\
\hline 12 & Kamila & 60 & Belum Tuntas & 65 & Tuntas \\
\hline 13 & Kirana & 45 & Belum Tuntas & 56 & Belum Tuntas \\
\hline 14 & Lintang & 50 & Belum Tuntas & 65 & Tuntas \\
\hline 15 & Bastiko & 52 & Belum Tuntas & 45 & Belum Tuntas \\
\hline 16 & Satrio & 58 & Belum Tuntas & 44 & Belum Tuntas \\
\hline 17 & Adam & 55 & Belum Tuntas & 69 & Tuntas \\
\hline 18 & Dafa & 60 & Belum Tuntas & 73 & Tuntas \\
\hline
\end{tabular}




\begin{tabular}{|c|c|c|c|c|c|}
\hline \multirow{2}{*}{ No. } & \multirow{2}{*}{ Nama } & \multicolumn{2}{|c|}{ Nilai UH sebelum PTK } & \multicolumn{2}{|c|}{ Nilai UH siklus I } \\
\hline & & Nilai & Keterangan & Nilai & Keterangan \\
\hline 19 & Dandi & 60 & Belum Tuntas & 65 & Tuntas \\
\hline 20 & Nabila & 58 & Belum Tuntas & 64 & Belum Tuntas \\
\hline 21 & Nadia & 48 & Belum Tuntas & 43 & Belum Tuntas \\
\hline 22 & Putri & 45 & Belum Tuntas & 49 & Belum Tuntas \\
\hline 23 & Raihan & 55 & Belum Tuntas & 65 & Tuntas \\
\hline 24 & Roiz & 50 & Belum Tuntas & 51 & Belum Tuntas \\
\hline 25 & Rudi & 48 & Belum Tuntas & 55 & Belum Tuntas \\
\hline 26 & Septeti & 52 & Belum Tuntas & 65 & Tuntas \\
\hline 27 & Septiana & 40 & Belum Tuntas & 72 & Tuntas \\
\hline 28 & Hani & 58 & Belum Tuntas & 70 & Tuntas \\
\hline 29 & Zuli & 55 & Belum Tuntas & 70 & Tuntas \\
\hline 30 & Zena & 60 & Belum Tuntas & 70 & Tuntas \\
\hline 31 & Jihan & 53 & Belum Tuntas & 65 & Belum Tuntas \\
\hline & Jumlah & 1612 & & 1830 & \\
\hline & Rata-rata & 52 & & 58,7 & \\
\hline & Persentase & & $0 \%$ & & $48,3 \%$ \\
\hline
\end{tabular}

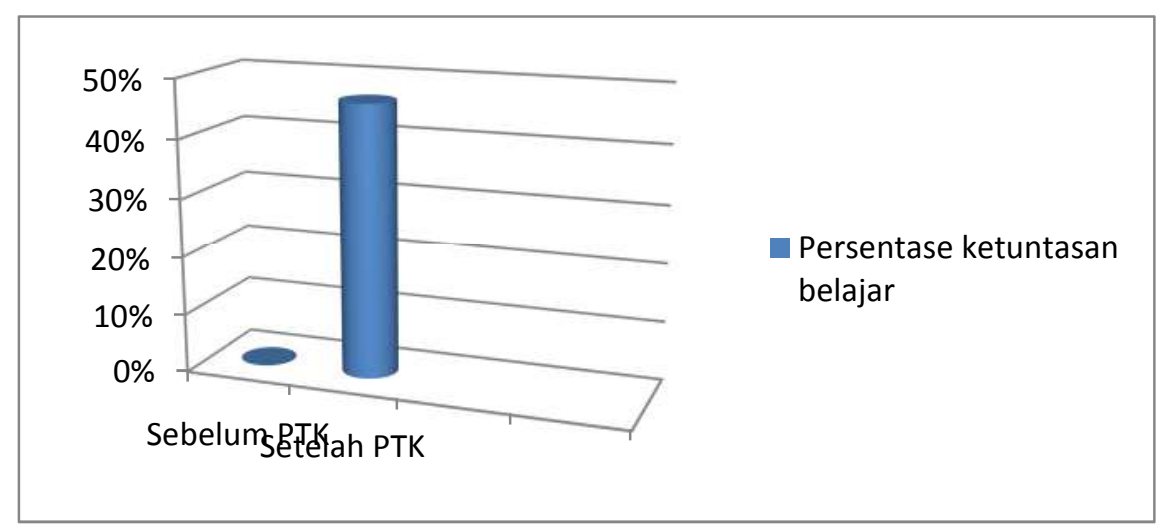

Diagram 2 Persentase ketuntasan belajar siswa siklus I

\section{Hasil Penelitian Siklus II}

\section{Motivasi Belajar}

Pemberian angket yang digunakan untuk mengetahui kondisi motivasi belajar siswa yang diberikan sebelum dilakukan tindakan dan sesudah siklus II. Analisa motivasi belajar siswa dapat dilihat pada tabel berikut:

Tabel 3. Hasil pengukuran motivasi belajar siswa siklus II

\begin{tabular}{|c|c|c|c|c|c|}
\hline \multirow{2}{*}{ No. } & \multicolumn{2}{|c|}{ Tindakan Siklus 1 } & \multicolumn{2}{c|}{ Tindakan Siklus 2 } & \multirow{2}{*}{ Kriteria } \\
\cline { 2 - 5 } & Jumlah Siswa & Persentase & Jumlah Siswa & Persentase & \\
\hline 1. & 17 & $54,8 \%$ & 21 & $67,8 \%$ & Sangat Tinggi \\
2. & 14 & $45,2 \%$ & 10 & $32,2 \%$ & Tinggi \\
\hline
\end{tabular}




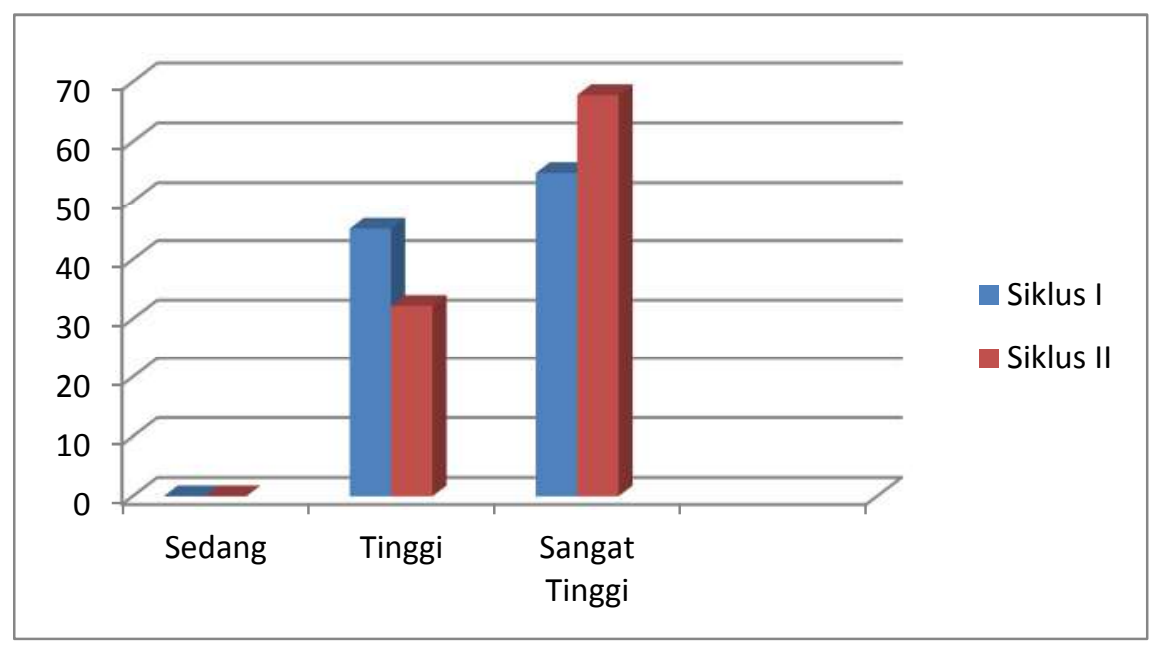

Diagram 3 Motivasi belajar siswa pada siklus II

\section{Hasil Belajar}

Pemberian tes pada akhir siklus dilakukan untuk mengetahui perbandingan hasil belajar siswa pada tindakan siklus I dan siklus II. Berikut hasil analisa hasil belajar siswa berdasarkan hasil ulangan harian pada siklus I dan siklus II:

Tabel 4 Hasil belajar siswa perbandingan siklus I dan siklus II

\begin{tabular}{|c|c|c|c|c|c|}
\hline \multirow{2}{*}{ No. } & \multirow{2}{*}{ Nama } & \multicolumn{2}{|c|}{ Nilai Siklus I } & \multicolumn{2}{c|}{ Nilai UH siklus II } \\
\cline { 3 - 6 } & & Nilai & Keterangan & Nilai & Keterangan \\
\hline 1 & Aiga & 50 & Belum Tuntas & 68 & Tuntas \\
\hline 2 & Anggi & 53 & Belum Tuntas & 70 & Tuntas \\
\hline 3 & Sabil & 42 & Belum Tuntas & 77 & Tuntas \\
\hline 4 & Daniel & 65 & Tuntas & 77 & Tuntas \\
\hline 5 & Erika & 67 & Tuntas & 70 & Tuntas \\
\hline 6 & Fadil & 46 & Belum Tuntas & 61 & Belum Tuntas \\
\hline 7 & Fajar & 48 & Belum Tuntas & 45 & Belum Tuntas \\
\hline 8 & Fara & 45 & Belum Tuntas & 72 & Tuntas \\
\hline 9 & Farhan & 67 & Tuntas & 42 & Belum Tuntas \\
\hline 10 & Fariz & 65 & Tuntas & 67 & Tuntas \\
\hline 11 & Fatimah & 61 & Belum Tuntas & 79 & Tuntas \\
\hline 12 & Kamila & 65 & Tuntas & 85 & Tuntas \\
\hline 13 & Kirana & 56 & Belum Tuntas & 50 & Belum Tuntas \\
\hline 14 & Lintang & 65 & Tuntas & 78 & Tuntas \\
\hline 15 & Bastiko & 45 & Belum Tuntas & 69 & Tuntas \\
\hline 16 & Satrio & 44 & Belum Tuntas & 85 & Tuntas \\
\hline 17 & Adam & 69 & Tuntas & 70 & Tuntas \\
\hline 18 & Dafa & 73 & Tuntas & 79 & Tuntas \\
\hline 19 & Dandi & 65 & Tuntas & 85 & Tuntas \\
\hline 20 & Nabila & 64 & Belum Tuntas & 74 & Tuntas \\
\hline 21 & Nadia & 43 & Belum Tuntas & 88 & Tuntas \\
\hline 22 & Putri & 49 & Belum Tuntas & 40 & Belum Tuntas \\
\hline 23 & Raihan & 65 & Tuntas & 76 & Tuntas \\
\hline 24 & Roiz & 51 & Belum Tuntas & 85 & Tuntas \\
\hline 25 & Rudi & 55 & Belum Tuntas & 75 & Tuntas \\
\hline 26 & Septeti & 65 & Tuntas & 88 & Tuntas \\
\hline 27 & Septiana & 72 & Tuntas & 87 & Tuntas \\
\hline 28 & Hani & 70 & Tuntas & 80 & Tuntas \\
\hline
\end{tabular}


138 | Wiwik Kusmawati, Penerapan Model Arias pada ...

\begin{tabular}{|c|c|c|c|c|c|}
\hline \multirow{2}{*}{ No. } & \multirow{2}{*}{ Nama } & \multicolumn{2}{|c|}{ Nilai Siklus I } & \multicolumn{2}{c|}{ Nilai UH siklus II } \\
\cline { 3 - 6 } & & Nilai & Keterangan & Nilai & Keterangan \\
\hline 29 & Zuli & 70 & Tuntas & 80 & Tuntas \\
\hline 30 & Zena & 70 & Tuntas & 87 & Tuntas \\
\hline 31 & Jihan & 65 & Belum Tuntas & 75 & Tuntas \\
\hline & Jumlah & $\mathbf{1 8 3 0}$ & & $\mathbf{2 2 6 4}$ & \\
\hline & Rata-rata & $\mathbf{5 8 , 7}$ & & $\mathbf{7 3 , \mathbf { 1 }}$ & \\
\hline & Persentase & & $\mathbf{4 8 , 3 \%}$ & & $\mathbf{8 3 , 9 \%}$ \\
\hline
\end{tabular}

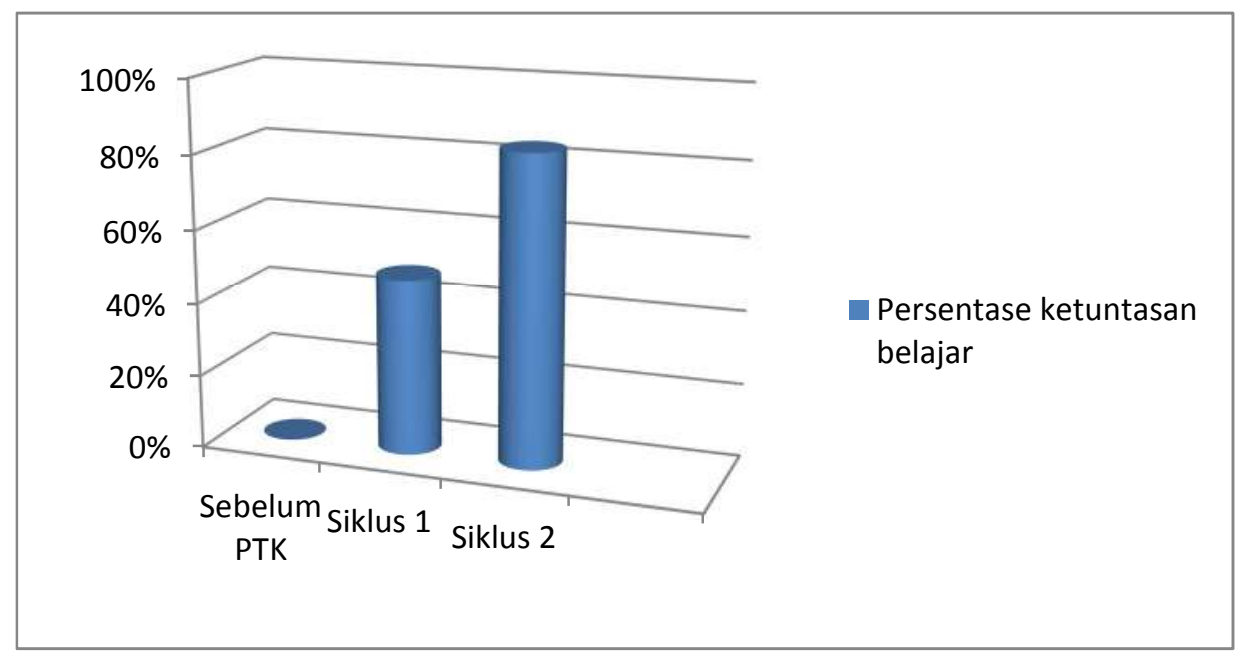

Diagram 4 Persentasi ketuntasan belajar siswa pada siklus II

\section{PEMBAHASAN}

1. Penerapan model pembelajaran ARIAS pada strategi pembelajaran kooperatif tipe Think-Pair-Share terhadap motivasi belajar siswa.

Pendidikan adalah tujuan sadar yang bertujuan untuk mengembangkan kualitas manusia sebagai suatu kegiatan yang sadar akan tujuan, maka dalam pelaksanaannya berada dalam suatu proses yang berkesinambungan dalam setiap jenis dan jenjang pendidikan semuanya berkaitan dalam suatu sistem pendidikan yang integral. Pendidikan di sekolah mempunyai tujuan untuk mengubah siswa agar dapat memiliki pengetahuan, keterampilan dan sikap pelajar sebagai bentuk perubahan perilaku hasil belajar (Syaiful dalam Mastuti 2009).

Motivasi adalah dorongan dari dalam diri siswa atau seseorang untuk melakukan sesuatu dalam rangka memenuhi kebutuhannya. Motivasi memegang peranan penting dalam belajar karena makin kuat motivasi seseorang dalam belajar maka makin optimal seseorang dalam melakukan aktivitas belajar (Fajar, 2007). Komponen-komponen motivasi itu sendiri meliputi attention (perhatian siswa terhadap pelajaran), relevance (keterkaitan materi pelajaran dengan kehidupan sehari-hari dan metode yang diinginkan siswa), confidence (kepercayaan diri siswa dalam mengikuti pelajaran) dan satisfaction (motivasi siswa terhadap penghargaan dalam mengikuiti pelajaran) (Arikunto, 2008).

Keberhasilan peningkatan mutu pendidikan, tentunya tidak terlepas dari proses pendidikan yang terkait dengan kegiatan belajar mengajar di kelas. Sebagai tenaga pengajar dan pendidik yang secara langsung terlibat dalam proses belajar mengajar, guru memegang peran penting dalam mengarahkan siswa mencapai hasil belajar yang maksimal. Salah satu kemampuan yang diharapkan dikuasai oleh guru biologi adalah bagaimana mengajarkan biologi dengan baik, dalam hal ini adalah memilih model pembelajaran yang relevan (Tenriawaru, 2009).

Menurut Manzilatusifa (2010) menyatakan bahwa, kegiatan pembelajaran yang melahirkan interaksi adalah sebagai suatu motivasi dalam rangka mencapai tujuan pembelajaran. Belajar merupakan kegiatan aktif siswa dalam membangun makna dan pemahaman. Motivasi yang timbul dari dirinya untuk berbuat sesuatu munculsecarakodratidaridirimanusiaitusendiri disebut motivasi intrinsik, sedangkan manusia 
yang menyebabkan mampu melaksanakan tugas dengan maksimal karena ada dorongan dari luar disebut motivasi ekstrinsik. Dengan demikian guru diharapkan merupakan orang yang karena profesinya sanggup menimbulkan dan mengembangkan motivasi untuk kepentingan proses pembelajaran di dalam kelas. Dengan motivasi dari guru merupakan faktor yang berarti dalam pencapaian tujuan pembelajaran. Dua pembangkit motivasi belajar yang efektif adalah keingintahuan dan keyakinan dalam kemampuan diri. Setiap siswa memiliki rasa ingin tahu, maka guru perlu memotivasi dengan pertanyaan diluar kebiasaan atau tugas yang menantang disertai penguatan bahwa siswa mampu melakukannya.

Sebagai upaya meningkatkan motivasi belajar siswa, maka perlu diciptakan suasana belajar dan interaksi baik, sehingga guru maupun siswa lain dapat berperan sebagai penyokong motivasi tersebut agar dapat muncul, sehingga keinginan untuk belajar juga meningkat. Penggunaan model pembelajaran ARIAS menekankan upaya dalam meningkatkan motivasi belajar siswa melalui komponen-komponen yang terkandung di dalamnya.

Berdasarkan hasil penelitian yang dilaksanakan terhadap siswa kelas VIII AMTs Al-Amin Pakis didapatkan adanya peningkatan motivasi belajar siswa, hal ini dapat dilihat dari data hasil analisis sebelum dilakukan tindakan, tindakan siklus I dan tindakan siklus II.
13\%. Selain suasana pembelajaran,guru dan lingkungan, diri siswa itu sendiri juga menjadi faktor utama keadaan motivasi belajar. Faktor yang ada pada diri organisme itu sendiri yang kita sebut faktor individual. Yang termasuk ke dalam faktor individual antara lain: faktor kematangan/pertumbuhan, kecerdasan, latihan, motivasi dan faktor pribadi. Faktor yang ada di luar individu yang kita sebut faktor sosial. Yang termasuk faktor sosial antara lain faktor keluarga/keadaan rumah tangga, guru dan cara mengajarnya, alat-alat yang dipergunakan dalam belajar-mengajar, lingkungan dan kesempatan yang tersedia dan motivasi sosial (Habibi, 2007).

2. Penerapan model pembelajaran ARIAS pada strategi pembelajaran kooperatif tipe Think-Pair-Share terhadap peningkatan hasil belajar siswa.

Belajar adalah kegiatan yang berproses dan merupakan unsur yang sangat fundamental dalam setiap penyelenggaraan jenis dan jenjang pendidikan. Ini berarti bahwa berhasil atau gagalnya pencapaian tujuan pendidikan itu amat tergantung pada proses belajar yang dialami siswa, baik ketika ia berada di sekolah maupun di lingkungan rumah atau keluarga. Belajar atau learning, adalah perubahan yang secara relatif berlangsung lama pada perilaku yang diperoleh dari pengalaman-pengalaman. Belajar

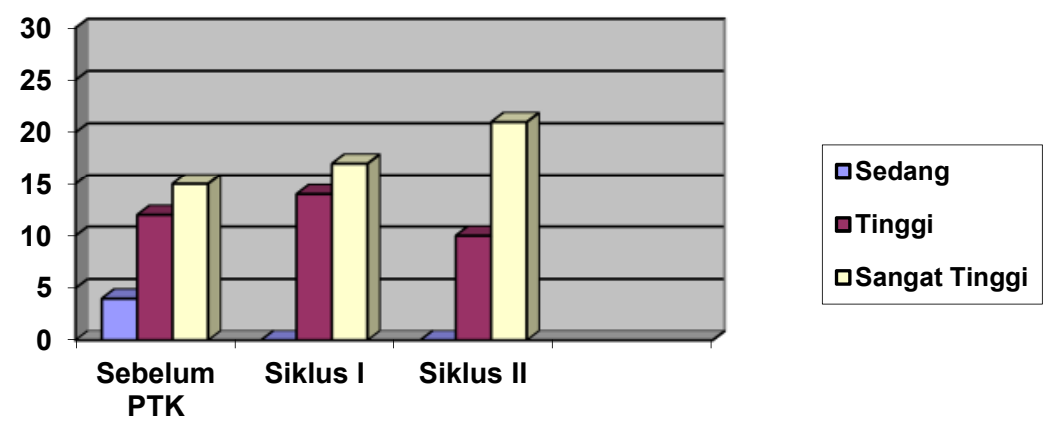

Diagram 5 Peningkatan motivasi belajar siswa

Penggunaan model pembelajaran ARIAS pada strategi pembelajaran kooperatif tipe Think-Pair-Share telah meningkatkan motivasi belajar siswa kelas VIII A MTs Al-Amin Pakis. Peningkatan motivasi belajar siswa dilihat dari jumlah siswa yang masuk dalam kategori sangat tinggi mengalami penambahan dari 15 siswa menjadi 17 siswa pada siklus I dan 21 siswa pada siklus II. Peningkatan persentase sebesar merupakan salahsatu bentuk perilaku yang amat penting bagi kelangsungan hidup manusia. Belajar membantu manusia menyesuaikan diri (adaptasi) dengan lingkungan (Muhibbin dalam Risa, 2009).

Kualitas pembelajaran pada suatu sekolah dapat dilihat dari segi proses dan segi hasil pembelajaran pada sekolah tersebut. Apabila proses dan produknya baik, maka dapat 
dikatakan bahwa kualitas pembelajaran juga baik. Keberhasilan suatu pembelajaran dapat dipengaruhi oleh metode pembelajaran yang digunakan guru. Jika metode pembelajarannya menarik dan terpusat pada siswa (studentcentered learning) maka motivasi dan perhatian siswa akan terbangkitkan sehingga akan terjadi peningkatan interaksi siswa dengan siswa dan siswa dengan guru sehingga kualitas pembelajaran dapat meningkat (Mulyasa dalam Zulfah, 2006).

Hasil belajar adalah kemampuan-kemampuan yang dimiliki siswa setelah menerima pengalaman belajarnya, dan setiap usaha yang dilakukan dalam kegiatan pembelajaran baik oleh guru sebagai pengajar, maupun oleh peserta didik sebagai pelajar, bertujuan untuk mencapai prestasi yang setinggi-tingginyat (Bloom dalam Sudjana (2005). Menurut Slameto (2003:54-72) dalam Dewi (2007) terdapat faktor-faktor yang mempengaruhi belajar meliputi faktor intern dan ekstern.

Faktor-faktor intern antara lain :

1. Faktor jasmaniah, meliputi faktor kesehatan dan cacat tubuh.

2. Faktor psikilogis, meliputi inteligensi, perhatian, minat, bakat, motif, kematangan, dan kesiapan.

3. Faktor kelelahan, kelelahan pada seseorang walaupun sulit untuk dipisahkan tetapi dapat dibedakan menjadi dua macam, yaitu kelelahan jasmani dan kelelahan rohani (bersifat psikis).

Sedangkan faktor-faktor ekstern yang berpengaruh terhadap belajar dapat dikelompokkan menjadi 3 faktor antara lain :

1. Faktor keluarga, meliputi cara orang tua mendidik, relasi antaranggota keluarga, suasana rumah, keadaan ekonomi keluarga, pengertian orang tua, dan latar belakang kebudayaan.

2. Faktor sekolah, meliputi metode mengajar, kurikulum, relasi guru dengan siswa, relasi siswa dengan siswa, disiplin sekolah, alat pelajaran, waktu sekolah, standar pelajaran diatas ukuran, keadaan gedung, metode belajar, dan tugas rumah.

3. Faktor masyarakat, meliputi kegiatan siswa dalam masyarakat, mass media, teman bergaul, dan bentuk kehidupan masyarakat. Menurut Joko dalam Pujiati (2008), keberhasilan belajar siswa dipengaruhi oleh faktorfaktor, antara lain : waktu yang tersedia untuk menyelesaikan suatu bahan ajar, usaha yang dilakukan seseorang untuk menguasai bahan ajar, bakat seseorang yang sifatnya individual, kualitas pengajaran atau tingkat kejelasan pengajaran oleh guru, dan kemampuan siswa untuk mendapatkan manfaat yang optimal dalam proses pembelajaran.

\section{Tabel 5 Hasil belajar siswa}

\begin{tabular}{|c|c|c|c|}
\hline Tindakan & $\begin{array}{c}\text { Sebelum } \\
\text { PTK }\end{array}$ & Siklus I & Siklus II \\
\hline Ketuntasan & $0 \%$ & $48,3 \%$ & $83,9 \%$ \\
\hline Kriteria & $\begin{array}{c}\text { Sangat } \\
\text { kurang }\end{array}$ & Kurang & Baik \\
\hline
\end{tabular}

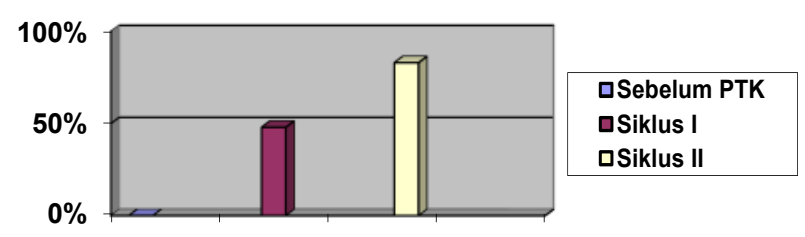

Diagram 6 Hasil belajar siswa

Jika pembelajaran pada materi pertumbuhan dan perkembangan menggunakan model pembelajaran ARIAS pada strategi pembelajaran kooperatif tipe Think-Pair-Share, maka akan dapat meningkatkan hasil belajar siswa kelas VIIIA MTs Al-Amin Pakis. Hal ini dapat dilihat dari peningkatan kriteria ketuntasan belajar ketika sebelum dilakukan tindakan, didapatkan $0 \%$, setelah dilakukan tindakan siklus I meningkat menjadi $48,3 \%$ sedangkan setelah tindakan siklus II meningkat lagi menjadi 83,9\%.

\section{KESIMPULAN DAN SARAN}

Berdasarkan hasil analisis data penelitian maka dapat disimpulkan :

1. Penggunaan model pembelajaran ARIAS pada strategi pembelajaran kooperatif tipe Think-Pair-Share, dapat meningkatkan motivasi belajar siswa kelas VIIIMTs Al-Amin Pakis dalam pokok bahasan pertumbuhan dan perkembangan. Hal ini dapat dilihat dari peningkatan motivasi belajar siswa pada kriteria sangat tinggi yaitu dari 54,8\% menjadi $67,8 \%$, peningkatannya sebesar $13 \%$. Sedangkan untuk kriteria tinggi, dari $45,2 \%$ turun menjadi 32,2\%. Penurunan prosentase sebesar $13 \%$ juga.

2. Penggunaan model pembelajaran ARIAS pada strategi pembelajaran kooperatif tipe 
Think-Pair-Share, dapat meningkatkan hasil belajar siswa kelas VIIIMTs Al-Amin Pakis dalam pokok bahasan pertumbuhan dan perkembangan. Hal ini dapat dilihat dari data hasil belajar siswa yang mengalami peningkatan, yaitu: sebelum dilakukan tindakan PTK, didapatkan 0\%, setelah dilakukan tindakan persentase keberhasilan siswa mengalami peningkatan yaitu dari 48,3\% termasuk dalam kriteria "kurang" menjadi 83,9\% dengan kriteria "baik".

\section{DAFTAR RUJUKAN}

Arikunto, S. 2008. Dasar-dasar Evaluasi Pendidikan. Bumi Aksara: Jakarta.

Arikunto, S. 1995. Prosedur Penelitian Suatu Pendekatan Praktis. PT. Rineka Cipta: Jakarta .

Arikunto, S. 2001.Penilaian Proses Hasil Belajar Mengajar. PT. Rieneka Cipta: Jakarta

Ariswoyo, D. 2007. IPA untuk Kelas VIII. Grafindo: Bandung.

Cakhary. 2009. Implementasi Model Pembelajaran Kooperatif Thing-Pair-Share (TPS) Pada Pokok Bahasan Zat Dan Wujudnya Di SMPN 1 Kalasan. (Jurnal Online). file:/ / / D:/index.php?view $=$ article $\% 3$ B\&catid $=43 \% 3$ Aartikel\&id $=53 \% 3 \mathrm{Am}$ odel-pembelajaran-kooperatif-thingpair-share\&format=pdf\&option $=$ com content \&Itemid =75. Tuesday, $24 \mathrm{March}$ 2009 12:26. Diakses: 28 Juni 2010.

Chotimah, H. \& Yuyun, 2009. Strategi-strategi Pembelajaran untuk Penelitian Tindakan Kelas. Surya Pena Gemilang: Malang.

Dewi, L. V. K. 2007. Penerapan Pembelajaran Model ARIAS Terintegrasi Pada Pembelajaran Kooperatif Tipe Think-Pair-Share Dalam Kegiatan Praktikum Mata Pelajaran Biologi di SMP Negeri 1 Panceng Gresik. Skripsi Tidak Diterbitkan.Jurusan Biologi FKIP Universitas Muhammadiyah Malang.

Dimyati dan Mudjiono. 2002. Belajar dan Pembelajaran. Rineka Cipta: Jakarta.

Fajar, 2006. Peningkatan Kualitas Pembelajaran Materi Pengelolaan Lingkungan Melalui Pembelajaran Koopratif JIGSAW Dengan Pendekatan JAS dan Penilaian Autentik di SMP Negeri 6 Semarang. Jurnal Penelitian. Jurusan Pendidikan Biologi MIPA Universitas Negeri Semarang.

Habibi, A. 2007. Implementasi Metode The Student Group Dalam Upaya Meningkatkan Moti- vasi Belajar Siswa Terhadap Mata Pelajaran Bahasa Arab XI A I MAN Malang I. Program Akta Mengajar IV Fakultas Tarbiyah Universitas Islam Negeri Malang. (Jurnal Online). Diakses: 28 Juni 2010.

Harlina, R. 2009. Penerapan Model Kooperatif Learning Tipe Think Pair Share (TPS) Terhadap Hasil Belajar Kimia Siswa Ppada Pokok Bahasan Sifat-sifat Larutan Elektrolit dan Non-elektrolit. (Jurnal Penelitian). Program studi Pendidikan Kimia Jurusan Pendidikan Ilmu Pengetahuan Alam Fakultas Ilmu Tarbiyah dan Keguruan Universitas Islam Negeri Syarif Hidayatullah Jakarta.

Ilhami, R. 2009. Meningkatkan Prestasi Belajar dengan Model ARIAS.http://www. koranpendidikan.com/profil-media. html. Diakses: 25 Juni 2010

Kiranawati. 2007. Model Pembelajaran ARIAS (online).http:/ / www.koranpendidikan. com/kategori/1/topik-utama.html. Diakses: 25 Juni 2010

Kusumah, W. 2008. Model-model Pembelajaran (online). http://wijayalabs.wordpress. com/about/. Diakses: 12 Juli 2010.

Manzilatusifa, U. 2010. Pemberian Motivasi Guru Dalam Pembelajaran (online). http:// virtuclass.e-fkipunla.net/. Diakses: 12 Juli 2010.

Mastuti, E. N. 2009. Meningkatkan Hasil Belajar Biologi dengan Model Pembelajaran Kooperatif Tipe TPS (Think Pair Share) Pada Siswa Kelas VIII D Smp Negeri 2 Gondang Sragen Tahun Pelajaran 2008/2009. Skripsi Tidak Diterbitkan. Fakultas Keguruan Dan Ilmu Pendidikan Universitas Muhammadiyah Surakarta 2009.

Pujiati, I. 2008. Peningkatan Motivasi dan Ketuntasan Belajar Matematika Melalui Pembelajaran Kooperatif Tipe Stad. Jurnal Ilmiah (Online).

Rahmawati, A. 2005. Penggunaan Pendekatan Kooperatif Model STAD Untuk Meningkatkan Hasil Belajar dan Aktifitas Siswa Dalam Mata Pelajaran Biologi Kelas 1 MAN Srono Banyuwangi. Skripsi Tidak Diterbitkan. Jurusan Biologi FKIP Universitas Muhammadiyah Malang.

Sriyati, S, dkk. 2008. Penerapan Pertanyaan Produktif dalamPembelajaran Biologi untuk Meningkatkan Kemampuan Kerja Ilmiah dan Pemahaman Konsep Siswa Di SMA. Jurusan Pendidikan Biologi FKIP Matematika dan Ilmu Pengetahuan Alam. 
142 | Wiwik Kusmawati, Penerapan Model Arias pada ...

Univeritas Pendidikan Indonesia. (Jurnal Online). Diakses: 28 Juni 2010.

Sudjana, N. 2005. Penilaian Proses Hasil Belajar Mengajar. PT. Remaja Rosda karya : Bandung

Susilo, H., Chotimah, Husnul \& Dwitasari, Y. 2009. Penelitian Tindakan Kelas. Banyumedia: Malang.

Tenriawaru, E. P. 2009. Peningkatan Motivasi, Aktivitas, Dan Hasil Belajar Biologi Siswa Melalui Penggunaan Model Pembelajaran KooperatifTipe Think-Pair And Share (TPS) Pada Siswa Kelas VIII1 SMP Negeri 30 Makassar. (Jurnal Online). http://epta86. blogspot.com/2009/07/think-pair-andshare.html. Diakses: 28 Juni 2010.
Wurianingrum, T. 2007. Meningkatkan Hasil Belajar Siswa Melalui Metode Observasi yang Divariasikan dengan LKS Word Square Pada Materi Klasifikasi Hewan di SMP Negeri 8 Purworejo. Jurnal Penelitian. Fakultas Matematika dan Ilmu Pengetahuan Alam. Universitas Negeri Semarang.

Zulfah. 2006. Meningkatkan kualitas pembelajaran materi Pengelolaan lingkungan dengan pendekatan jas Melalui pembelajaran kooperatif think-pair-share Dan penilaian autentik di SMPN 37 Semarang. Jurnal Penelitian Fakultas Matematika dan Ilmu Pengetahuan Alam. Universitas Negeri Semarang. 